\title{
From LCA to Life Cycle Sustainability Assessment: concept, practice and future directions
}

\author{
Alessandra Zamagni • Hanna-Leena Pesonen • \\ Thomas Swarr
}

Received: 3 August 2013 / Accepted: 18 August 2013 / Published online: 3 September 2013

(C) Springer-Verlag Berlin Heidelberg 2013

\section{Life Cycle Sustainability Assessment: where are we?}

More than 1 year ago, the subject area on Life Cycle Sustainability Assessment has been launched (Zamagni 2012) in order to provide a virtual place in which scientists from different disciplinary fields could discuss the main challenges in addressing sustainability with a life cycle perspective. The challenge has been taken on also by the editors of three subject areas that deal with sustainability from complementary angles-Life Cycle Sustainability Assessment (LCSA), Life Cycle Costing (LCC), and Social Life Cycle Assessment (SLCA). The result was the launch of a call for papers for a special issue on LCSA, whose results we are glad to present.

Our initiative took its point of departure from two facts: (1) sustainability has become quite a keyword in any decisioncontext situation and the scientific community has the duty to provide its contribution in demonstrating what might be sustainable and how to measure it with a scientific approach; (2) the life cycle approach is considered to provide a valuable support in integrating sustainability into the design, innovation, and evaluation of products and services, as can be seen in several environmental policies at the European and international level in which life cycle thinking represents the backbone.

A. Zamagni $(\bowtie)$

LCA and Ecodesign Laboratory, Enea, via Martiri di Monte Sole, 4, 40129 Bologna, Italy

e-mail: alessandra.zamagni@enea.it

H.-L. Pesonen

School of Business and Economics, University of Jyväskylä,

P.O. Box 35, 40014 Jyväskylä, Finland

T. Swarr

Sustainability by Design, Imagineers LLC, 8 Shultas Pl, Hartford, CT 06114, USA
As far as the timely and challenging aspects of sustainability are concerned, the EU has mainstreamed sustainable development into a broad range of its policies, such as the initiatives against climate change and the promotion of a low-carbon economy. The European Council (2009) confirmed that sustainable development remains a fundamental objective of the European Union under the Lisbon Treaty. Moreover, as emphasized in the Presidency's report on the review of the Union's Sustainable Development Strategy, the strategy will continue to provide a long-term vision and constitute the overarching policy framework for all Union policies and strategies (Council of the European Union 2009).

Sustainability is a concept that needs to be addressed not only at the policy level but also in the business context: many companies have included sustainability in their mission, also driven by an increasing demand for sustainable products by more aware consumers. Although the policy and the business context deal with sustainability in different ways, given the diversity of needs, a common element for both is the complexity entailed by the assessment. Such a complexity is due to the following main aspects, as pointed out by Heijungs et al. (2010)

- An answer to questions on sustainability requires normative elements, such as trade-offs between economy and environment, and aspects of inter- and intra-generational equity;

- A sustainability analysis involves self-denying prophecies (e.g., in predicting undesired consequences which will be combated before they have the chance to develop);

- Even the aspects that are factually true are in many cases badly known to scientists because they involve complex and novel phenomena.

Thus, from the analytical point of view different aspects have to be taken into account such as the following: 
- The scale of the assessment, which can range from the global level in which geopolitical implication are involved, to the continental, country, up to the regional and local scale;

- The time frame: How far into the future are we interested in looking at? We could be interested in understanding what will happen if a certain choice is made, what may happen if no action is taken, and how certain present problems may be solved in the future by choosing a certain strategy (Zamagni et al. 2012);

- Mechanisms to be addressed, i.e., connecting links between activities;

- Stakeholders and actors involved in the analysis, as the diversity of perspectives guides the choice of the modeling techniques to be applied and define the value system from which sustainability indicators are derived.

Regarding the second point, i.e., the relevance and role of the life cycle approach in addressing sustainability problems, an important contribution came from well-known international initiatives: the United Nations Environment Programme (UNEP)/Society of Environmental Toxicology and Chemistry (SETAC) "Life Cycle Initiative" (2009), which published the "Guidelines on SLCA" and in 2011, the "LCSA framework" (UNEP/SETAC 2011); SETAC, which promoted a "Code of Practice on LCC" (Swarr et al. 2011), and the European Commission, which recently published the "Product Environmental Footprint (Commission Recommendation 2013/179/ EU)," as a contribution towards the harmonization of Life Cycle Assessment (LCA) practice. The main drivers for these developments were given by the recognition that the life cycle approach is rooted into the sustainability concept for the following characteristics: (1) the system thinking, i.e., the capability of understanding and addressing a system by analyzing the linkages and interactions between the elements that compose the entirety of the system; (2) the interdisciplinary approach, whose most evident example is given in the impact assessment phase. Thus, the scientific community started questioning how LCA could contribute to address sustainability and in response, many developments have been occurred in terms of methods, models, and frameworks.

Frameworks, methods, models, and tools are now available for being used and tested in several applications, thanks also to the initiatives of the European Commission that in some technological projects of the $7^{\circ}$ Framework Project has required as mandatory the application of the LCSA framework for the sustainability assessment of new and innovative environmental technologies.

Despite the young history of LCSA framework and life cycle-based methods for addressing sustainability such as SLCA, we think it is important to make an appraisal in order to understand where we are and whether we are on the right track: are the methods and tools developed so far able to address sustainability questions in business and policy context?

With this special issue we have invited scientists to attempt an answer to this question, to critically discuss the topic of sustainability assessment at least form three perspectives as follows: (1) concept, i.e., ontology, epistemology, and methodology of LCSA; (2) practice, i.e., case studies and examples of applications of LCSA frameworks; (3) future directions, i.e., how to further develop LCSA, which research strategies and lines are considered relevant.

In the following sections, the contributions received have been structured along these three perspectives, bringing out the main outcomes and insights.

\section{Concept}

We have opened this editorial pointing out the relevance of a life cycle approach in the transition towards Sustainable Production and Consumption patterns, and the response of the scientific community, which started working on the development and tuning of methods able to quantify these patterns, in order to provide sound and scientific-based support to policy making. However, the contributions of this special issue bring this common belief into question and discuss where and how to position the life cycle approach in the context of sustainability. It might be surprising, and some readers could question the relevance of this aspect, but we strongly believe that this awareness and a reflection on it is the passé-partout for understanding the following: (1) why research on sustainability is progressing slowly and (2) in which directions the research should go.

The role of the different life cycle-based methods, such as LCA and SLCA, and the relevance of life cycle thinking (LCT) are discussed by Parent et al. (2012). The authors highlight that, in particular, the social dimension of sustainable development is seldom discussed in the context of Statistical Process Control (SPC), and also note that SLCA inadequately addresses the social impacts of products on consumers. The methodology is partly rooted in the field of Corporate Social Responsibility, and is therefore more focused on the behaviors of enterprises. For LCA or SLCA to affect change, the analyses must drive actions that yield broader market incentives. The authors differentiate situations where the appropriate perspective is "ability to act on" from those requiring a life cycle perspective. With this contribution, the importance of framing the use of LCSA tools in their context of use is demonstrated, as pointed out also by Sala et al. (2012a, b), Hu et al. (2013).

The role of LCT is discussed also by Sala et al. (2012a), who frame the overall discussion in the context of Sustainability Science (SS). SS emerged as a discipline in which the sustainability concepts has its roots and provided a vision of 
what a sustainability assessment should entail. In this vision, the life cycle concept is inherently there, as SS calls for a holistic approach. A meta-review of comparative studies on sustainability assessments (SA) was performed by the authors to identify key criteria for developing and assessing SA methods and, in particular, life cycle-based methodologies. An interesting finding was that there is little mention of life cycle thinking or assessment. The authors noted this was worthy of future research to determine if it indicates simply a lack of exchange between the two research communities, or whether in fact life cycle methods are not fully suitable for dealing with the complexity entailed by SS, which requires a trans-disciplinary framework characterized by: holistic and system wide approaches, shift from multi- towards transdisciplinarity; multi-scale (temporal and geographical) perspectives, and better involvement and participation of stakeholders.

Talking about sustainability, in the LCA community, a common and widely used abbreviation for a life cycle-based sustainability assessment framework is the acronym LCSA: it refers to the evaluation of environmental, social, and economic impact and benefit of a product throughout its life cycle. The idea of combining three LCA techniques into one has been theorized since 2008 (Kloepffer 2008), and recently, the publication "Towards a Life Cycle Sustainability Assessment (LCSA)," presented in this special issue by Valdivia et al. (2012), shows the feasibility of this approach and framework, together with its potential benefits.

However, the LCSA abbreviation is also used to indicate another framework, i.e. Life Cycle Sustainability Analysis (LCSA analysis), proposed by Guinée et al. (2011), which is able to accommodate knowledge from different disciplines relevant to sustainability and to better link questions to models of analysis towards trans-disciplinarity. Sala et al. (2012b) analyze the two sustainability frameworks, i.e., LCSA (assessment) and LCSA (analysis), against the key criteria for addressing sustainability according to SS. LCSA (assessment) separately models each pillar of sustainability, and then synthesizes the results in a final decision-analysis step. While this has the advantage of promoting a strong sustainability perspective, the authors suggest this approach fails to consider mutual relations amongst the pillars and detracts from a holistic understanding of the system. LCSA (analysis) avoids this problem by offering an integrated framework, but the authors recognize the approach has been developed only as a conceptual framework and needs to be made operational. Their evaluation of the two approaches against the key criteria for SA is used to develop recommendation for the further development of LCSA and collaboration between life cycle and SS research communities. A final observation relevant to both is that life cycle methods should be expanded from a focus on avoiding negative impacts to also proactively enhancing positive impacts, and to do this in a manner that contributes to sustainable development.
The LCSA (analysis) framework, as discussed in Sala et al. (2012a, b) is characterized also by values, which cannot be realistically separated by facts. Bachmann (2012) in his article discusses the ability of total costs approach and multi-criteria decision analysis (MCDA) to provide a framework for interpreting results involving value choices. Moreover, the author provides a perspective on how these methods can support the development of LCSA, identifying differences and complementarities between MCDA, total costs, and current LCSA methods, and raising important questions: whether the analysis in LCSA shall be distinguished into the three dimensions (environmental, economic, social) at the inventory level or the impact assessment level; whether exceptional events needs to be addressed in LCSA; how to deal with value choices; and how to include positive impacts in the assessment.

After discussing the foundations of LCSA, the framework for evaluating it and how to position and take into account values and perspectives, the role of the different methods in LCSA needs to be discussed. One of the most controversial methods used in the LCSA framework is LCC. Already, Jorgensen et al. (2010) discussed the relevance of LCC into LCSA, and the question is iterated by Wood and Hertwich (2012), who discusses the role of LCC starting from the following consideration. Sustainability is a concept defined at macro level, and key to economic sustainability is the functioning of the economic system on the macro level. Thus, the authors point out that LCC is a useful indicator in economic assessment, but it fails to capture the full dimension of economic sustainability, given - among others - its inherent contradiction between user goals (minimization of costs) and societal goals (maximization of value adding). The authors suggest that LCSA needs to go beyond LCC, looking for indicators of economic impact able to address long-term economic sustainability and not just short-term economic cost.

\section{Practice}

Although at theoretical and conceptual level the development process is still ongoing, many practitioners started implementing the LCSA framework or the single life cycle-based methods, in order to test their ability to measure sustainability or its subsets (e.g., economic and environmental aspects). A proposal of a computational structure for LCA and LCC, together with an explicit and transparent description of how to actually calculate the life cycle costs, has been provided by Heijungs et al. (2012). The main advantage of the proposed solution is that all methodological choices are made consistently for the LCA and the LCC, and an eco-efficiency indicator can be easily calculated within the framework of LCSA. Going further, the authors point out that economics is more than costs, 
and other aspects such as return on investment, job creation, and growth are of interest in a sustainability analysis, recalling the main outcomes of the analysis of Wood and Hertwich (2012).

An example of integration between LCA and LCC is provided by Simões et al. (2013), comparing two possible material alternatives (stainless steel and glass fiber reinforced polymer composite) for a storage tank. Results represent a win-win situation, while the composite tank has a globally preferable environmental and economic profile; its impacts are, in fact, lower in all life cycle stages compared to the steel tank. An alternative way of combining LCA and LCC is presented by Bernier et al. (2013): they propose the use of eco-costs as a weighting method in LCA, thereby bringing the issue of monetizing the environmental impacts on the agenda. According to the authors, the method provides a single-score impact assessment method relevant to decision making as well as a straightforward approach to LCA interpretation. In the given case study of a natural gas combined power plant, three scenarios to reduce $\mathrm{CO}_{2}$ emissions are examined using the suggested method.

Moving from integration between LCA and LCC to the inclusion of also social aspects with SLCA, a method to visualize the interchange and trade-off between results of LCA, LCC, and SLCA has been proposed, based on multidimensional Pareto (Ostermeyer et al. 2013). The method, tested in a case study of refurbishment of residential buildings, combines LCA and LCC, and a visible Pareto optimal curve can be observed in the results, which points to the potential of the method.

Pesonen and Horn (2012) observed that less attention has been given to understanding the overall management tools of LCSA and propose a sustainability strength-weaknessopportunity-threat (SWOT) tool to speed the assessment process and more readily communicate the results to key decision makers. Their analytical tool combines the SWOT tool, which is well-established in strategic business planning, with streamlined LCA methods. Their approach does address all three pillars in an integrated framework, and uses a qualitative 3level valuation indicator to model significance. However, the authors note that the effective use of the tool depends on engaging with an extended community of stakeholders with differing perspectives, and that it is best used as a cooperative brainstorming tool. A survey of some 111 organizations that have used the tool over the past 5 years offered encouraging results, indicating that use of the tool led to actual changes in $57 \%$ of the cases. The authors offer a framework for evaluating the survey responses that could be usefully applied to other studies. Responses were evaluated for impacting various levels of change - the organization itself, its industrial network, end users, and finally the institutional context. The study demonstrated that even with a streamlined method, business decision makers were able to identify potential improvements and were motivated to actually implement change.

The case studies described so far make reference to the LCSA (assessment) framework, as described in Kloepffer (2008) and Valdivia et al. (2012), and are mainly aimed at testing its feasibility and at understanding what kind of information can be obtained and how they can support the decision making process. The LCSA (analysis) framework is still at the conceptual level, and needs to be made operational. Besides the illustrative case studies described in Zamagni et al. (2009), in this special issue, we publish the first application of the LCSA (analysis) on the case of concrete recycling. Hu et al. (2013) have developed a procedural approach to implement the LCSA framework, articulated into 5 steps. The authors present the first three, which are aimed at defining the goals and scope of the analysis. The result of the procedure is the definition of different sub-questions for the sustainability problem at hand, depending on the scale of the analysis and of the consequences, and on the stakeholders involved. The authors show that a practical approach to model the impacts of a broad system is to start by modeling the technological system at the micro level and then scale it up with realistic scenarios setting, generated with the knowledge gained from studies at a higher level of the analysis (e.g., material flow analysis at the territorial level and policy/economic studies at the macro level). Additional case studies are necessary to move the LCSA (analysis) into a practical framework, but the preliminary steps for its operationalization are set.

\section{Future directions}

The contributions collected in this special issue shows that the number of applications of LCSA is still limited, and the majority of the examples occur at the interface of environmental and economic aspects. Social aspects are less addressed, and despite the difficulties at practical level — data and indicators - there is still a weak understanding at the conceptual level, both for SLCA and LCSA. The LCSA (assessment) approach is the most developed, but has been criticized for a mechanistic perspective that prevents full understanding of the mutual interdependencies of the three pillars of sustainability. Questions of scope are also raised. Is the appropriate scale products, enterprises, communities, or nations? Sustainability is the collective result of many independent but interrelated choices. Several contributors emphasized the need to consider the methodologies within the context of their use and to engage a broad range of stakeholders with different perspectives to co-create solutions that can move us toward SPC patterns. There will be a continued need to further refine and develop measures of each of the pillars of sustainability, while at the same time promoting social processes to encourage learning and adaptation from inadequately modeled and understood dependencies between 
the pillars. Even if an understanding of the complex relationships among the pillars is developed, there remains the social challenge of influencing those many individual choices to recognize and respond to their collective impact. Sterman (2002) observed that all models are wrong, but some are useful. LCSA, as noted in the contributions, will need to expand its goal beyond targeting hotspots and minimizing negative impacts to developing positive solutions and encouraging social learning and adaptation, and accept the inherent uncertainty and ignorance that characterizes any sustainability assessment.

\section{References}

Bachmann TM (2012) Towards life cycle sustainability assessment: drawing on the NEEDS project's total cost and multi-criteria decision analysis ranking methods. Int J Life Cycle Assess. doi:10.1007/ s11367-012-0535-3 (this issue)

Bernier E, Maréchal F, Samson R (2013) Life cycle optimization of energy-intensive processes using eco-costs. Int J Life Cycle Assess. doi:10.1007/s11367-013-0560-x (this issue)

Commission Recommendation (2013/179/EU) on the use of common methods to measure and communicate the life cycle environmental performance of products and organisations. Annex II: Product Environmental Footprint (PEF) guide

Council of the European Union (2009) Review of the EU sustainable development strategy_Presidency Report. 16818/09 Brussels, 1 December 2009

European Council (2009) 10/11 December 2009 Conclusions. EUCO 6/ 09 Brussels, 11 December 2009

Guinée JB, Heijungs R, Huppes G, Zamagni A, Masoni P, Buonamici R, Ekvall T, Rydberg T (2011) Life cycle assessment: past, present, and future. Environ Sci Technol 45:90-96

Heijungs R, Huppes G, Guinée JB (2010) Life cycle assessment and sustainability analysis of products, materials and technologies. Toward a scientific framework for sustainability life cycle analysis. Polym Degrad Stab 95(3):422-428

Heijungs R, Settanni E, Guinée J (2012) Toward a computational structure for life cycle sustainability analysis: unifying LCA and LCC. Int J Life Cycle Assess. doi:10.1007/s11367-012-0461-4 (this issue)

Hu M, Kleijn R, Bozhilova-Kisheva KP, Di Maio F (2013) An approach to LCSA: the case of concrete recycling. Int J Life Cycle Assess. doi: $10.1007 / \mathrm{s} 11367-013-0599-8$ (this issue)

Jørgensen A, Hermann I, Mortensen JB (2010) Is LCC relevant in a sustainability assessment? Int J Life Cycle Assess 15:531-532
Kloepffer W (2008) Life cycle sustainability assessment of products. Int J Life Cycle Assess 13(2):89-95

Ostermeyer Y, Wallbaum H, Reuter F (2013) Multidimensional Pareto optimization as an approach for site-specific building refurbishment solutions applicable for life cycle sustainability assessment. Int $\mathrm{J}$ Life Cycle Assess. doi:10.1007/s11367-012-0548-6 (this issue)

Parent J, Cucuzzella C, Revéret JP (2012) Revisiting the role of LCA and SLCA in the transition towards sustainable production and consumption. Int J Life Cycle Assess. doi:10.1007/s11367-012-0485-9 (this issue)

Pesonen HL, Horn S (2012) Evaluating the sustainability SWOT as a streamlined tool for life cycle sustainability assessment. Int J Life Cycle Assess. doi:10.1007/s11367-012-0456-1 (this issue)

Sala S, Farioli F, Zamagni A (2012a) Progress in sustainability science: lesson learnt from current methodologies for sustainability assessment. Part I. Int J Life Cycle Assess. doi:10.1007/s11367-012-0508-6 (this issue)

Sala S, Farioli F, Zamagni A (2012b) Life cycle sustainability assessment in the context of sustainability science progress. Part II. Int J Life Cycle Assess. doi:10.1007/s11367-012-0509-5 (this issue)

Simões CL, Costa Pinto LM, Simões R, Bernardo CA (2013) Integrating environmental and economic life cycle analysis in product development: a material selection case study. Int J Life Cycle Assess. doi:10. 1007/s11367-013-0561-9 (this issue)

Sterman JD (2002) All models are wrong: reflections on becoming a systems scientist. Syst Dyn Rev 18(4):501-531

Swarr T, Hunkeler D et al (2011) Environmental life cycle costing: a code of practice. Society of Environmental Toxicology and Chemistry, Pensacola

UNEP/SETAC (2009) Guidelines for Social Life Cycle Assessment of products. ISBN No 978-92-807-3021-0, UNEP/SETAC, Paris

UNEP/SETAC (2011) Towards a life cycle sustainability assessment. ISBN No: 978-92-807-3175-0, UNEP/SETAC, Paris

Valdivia S, Ugaya CML, Hildenbrand J, Traverso M, Mazijn B, Sonnemann G (2012) A UNEP/SETAC approach towards a life cycle sustainability assessment - our contribution to Rio +20 . Int $\mathrm{J}$ Life Cycle Assess. doi:10.1007/s11367-012-0529-1 (this issue)

Wood R, Hertwich EG (2012) Economic modelling and indicators in life cycle sustainability assessment. Int J Life Cycle Assess. doi:10. 1007/s11367-012-0463-2 (this issue)

Zamagni A (2012) Life cycle sustainability assessment. Int J Life Cycle Assess 17:373-376

Zamagni A, Buttol P, Buonamici R, Masoni P, Guinée J, Huppes J, Heijungs R, van der Voet E, Ekvall T, Rydberg T (2009) Blue paper on Life Cycle Sustainability Analysis. Technical report of CALCAS project. www.calcasproject.net. Accessed July 2014

Zamagni A, Guinée J, Heijungs R, Masoni P (2012) Life Cycle Sustainability Analysis. In: Curran MA (ed) Life Cycle Assessment: A Guide for Environmentally Sustainable Products. Wiley, ISBN: 9781118099728 